\title{
Auditoria interna como instrumento de controle social na administração pública
}

Célia Marçola

\begin{abstract}
Não é a Constituição perfeita, mas será útil, pioneira e desbravadora.
Será luz, ainda que de lamparina, na noite dos desgraçados.

É caminhando que se abrem os caminhos.

Ela vai caminhar e abri-los.
\end{abstract}

Ulisses Guimarães

\section{Introdução}

"Declaro promulgado o documento da liberdade, da democracia e da justiça social do Brasil”. Com essas palavras Ulisses Guimarães, presidente da Assembleia Nacional Constituinte, fazia o país conhecer na data de 5 de outubro de 1988 a nova Constituição da República Federativa do Brasil, após décadas de convívio com um regime militar autoritário e ditatorial. A Constituição de 1988 foi inspirada no direito constitucional norte-americano e como um desdobramento dos ensinamentos preconizados por Montesquieu. O autor doutrinou que o Estado pode corromper-se a ponto de desaparecer o espírito público como consequência do abuso do poder político. Para evitar esse abuso propôs a tripartição do poder combinado"para formar um Governo Moderado é necessário combinar os Poderes, regrá-los, temperá-los, fazê-los agir; dar a um Poder, por assim dizer, um lastro, para pô-lo em condições de resistir um ao outro".

A Carta Magna brasileira seguiu esses preceitos e definiu como principais instituições políticas: a República, a divisão dos poderes em Executivo, Legislativo e Judiciário, e a garantia dos direitos fundamentais dos cidadãos.

Montesquieu também asseverou em sua doutrina que "É experiência eterna a de que todo homem que tem o poder é levado a abusar dele. Caminha até que 
encontre limites. Para que não se possa abusar do poder, é preciso que, pela disposição das coisas, o poder detenha o poder". Nesse sentido, o uso do poder pelo administrador público deve sofrer controle e interferência capazes de agir como freio ao arbítrio, à improvisação e à irresponsabilidade administrativa. $\mathrm{Na}$ atual Constituição Federal o "sistema de freios", no âmbito da administração pública, corresponde aos controles interno e externo, conforme definido no artigo 70 :

Art. 70: A fiscalização contábil, financeira, orçamentária, operacional e patrimonial da União e das entidades da administração direta, indireta, quanto à legalidade, legitimidade, economicidade, aplicação de subvenções e renúncia de receitas, será exercida pelo Congresso Nacional, mediante controle externo, $e$ pelo sistema de controle interno de cada poder (grifo nosso).

Antes disso, o sistema de controle já havia sido recepcionado pela primeira vez na Constituição de 1967, e positivado no Decreto-Lei no 200/67 que determinava, no artigo 6" "Dos Princípios Fundamentais":

Art. $6^{\circ}$ As atividades da Administração Federal obedecerão aos seguintes princípios fundamentais:

I - Planejamento.

II - Coordenação.

III - Descentralização.

IV - Delegação de Competência.

$V$ - Controle.

(Decreto-Lei n ${ }^{\circ} 200$ de 25 de fevereiro de 1967, grifo nosso).

E especificamente no Capítulo V, no que concerne ao sistema de controle na administração:
Art. $13 \mathrm{O}$ controle das atividades da Administração Federal deverá exercerse em todos os níveis e em todos os órgãos, compreendendo, particularmente:

a) o controle, pela chefia competente, da execução dos programas e da observância das normas que governam a atividade específica do órgão controlado;

b) o controle, pelos órgãos próprios de cada sistema, da observância das normas gerais que regulam o exercício das atividades auxiliares;

c) o controle da aplicação dos dinheiros públicos e da guarda dos bens da União pelos órgãos próprios do sistema de contabilidade e auditoria. (Decreto-Lei ${ }^{\circ}$ 200 de 25 de fevereiro de 1967).

Seguramente, o Decreto-Lei no 200/ 67 foi o instrumento que teve o condão de positivar, entre as responsabilidades da administração pública, o controle interno do próprio administrador sobre o seu fazer (controle interno administrativo), inaugurando, inclusive, as auditorias de caráter financeiro e orçamentário.

No entanto, apesar de meio útil e imprescindível da administração, muito comumente surgem dúvidas quanto ao que, de fato, seja controle interno. Para fins deste trabalho, o conceito que será aqui exposto trata do controle interno não como imposição legal e burocrática de controle dos atos, ações e resultados do administrador público. A definição adotada conceitua o controle interno como processo, do dia a dia, realizado pela direção, ou seja, por pessoa responsável por dirigir as atividades da área que coordena, como, por exemplo, área de compras, financeira, entre outras, com propósito de fornecer segurança 
sobre os objetivos a serem alcançados. Controle interno, portanto, é uma ação traçada por pessoas que dirigem a organização com a finalidade de minimizar os riscos e aumentar as chances de atingir determinado fim. No caso da administração pública, o controle interno assegura ainda que, afora o planejamento de atividades, estas estejam calçadas ainda pelos princípios constitucionais da legalidade, impessoalidade, moralidade, publicidade e eficiência, esse último assegurado por meio da Emenda Constitucional $n^{\circ}$ 19/98. Portanto, toda e qualquer organização pública possui controle interno, até mesmo com a finalidade de combater as improvisações e a irresponsabilidade administrativa, evitando prejuízos sociais e econômicos.

O controle interno é, deste modo, obrigatório e inerente às atividades do administrador público e a sua confiabilidade e eficiência são verificadas pelos órgãos de controle externo, como é o caso dos tribunais de contas. Esses órgãos são autônomos e independentes da administração, nunca participando dos atos por ela praticados, cabendo-lhes monitorar e exercer a fiscalização. As atuações dos órgãos de controle externo são de extrema importância na vigilância do poder público e não se limitam apenas à fiscalização posterior dos atos praticados. Sua fiscalização está assegurada também pelo "poder geral de cautela", conforme entendimento do Supremo Tribunal Federal:

"O TCU tem competência para fiscalizar procedimentos de licitação, determinar suspensão cautelar (arts. $4^{\circ}$ e 113 , ds $1^{\circ}$ e $2^{\circ}$, da Lei no $\left.8.666 / 93\right)$, examinar editais de licitação publicados e, nos termos do artigo 276 do Regimento Interno, possui legitimidade para a expedição de medidas cautelares para prevenir lesão ao erário e garantir a efetividade de suas decisões".

(GraciE, Ellen, MS no 24.510-7 STF).

Como se vê, os administradores públicos ficam obrigados a recepcionar as auditorias externas dos tribunais de contas, inclusive tendo seus atos fiscalizados preventivamente, se assim entender necessário o órgão de controle externo. Tal

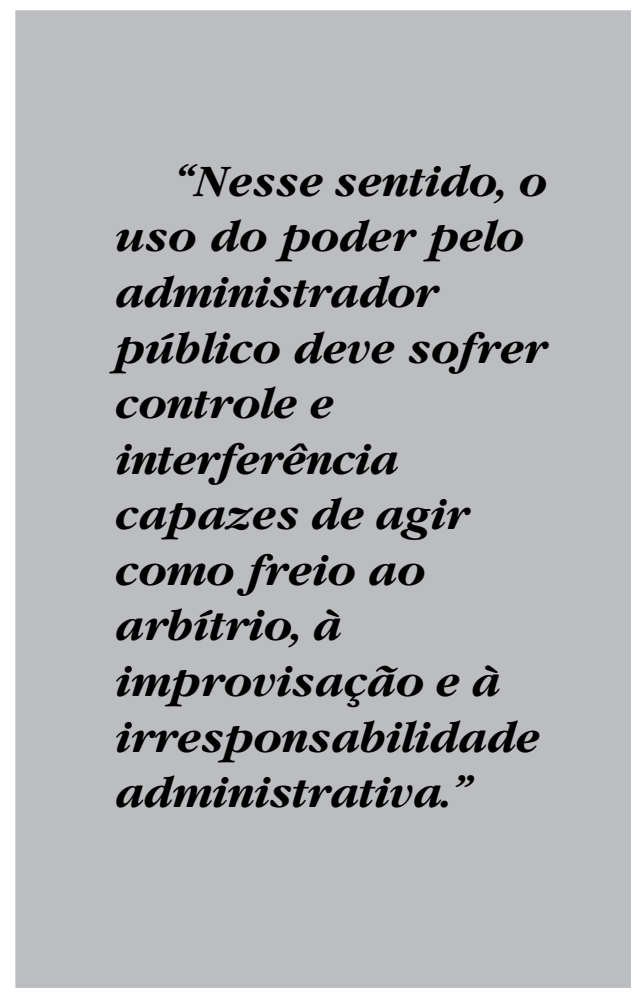

submissão da administração pública ao controle externo é uma decorrência do Estado de Direito, já que, conforme referencia Hely Lopes Meirelles (1988), os controles referem-se a "faculdade de vigilância, orientação e correção que um poder, órgão ou autoridade exerce sobre a conduta funcional de outro". Sem controle não seria possível assegurar a 
responsabilidade pública, que depende de uma fiscalização contumaz dos atos do Estado, como pressuposto dos princípios constitucionais citados. A propósito disso, Silva (2000) argumenta que os princípios fundamentais da administração pública encontram-se positivados na Constituição e "Possuem eficácia jurídica direta e imediata e exercem a função de diretrizes superiores do sistema, vinculando a atuação dos operadores jurídicos na aplicação das normas ao respeito dos mesmos". O mesmo autor ressalta ainda que os princípios constitucionais "são vigas mestras a sustentar todo o ordenamento jurídico do Estado".

Por último, é possível aferir, portanto, que o controle externo e o interno propiciam a avaliação permanente dos atos praticados pelo gestor público, em decorrência do uso do poder que lhe é outorgado pela sociedade, sendo correto dizer ainda que os controles são como mecanismos de preservação das instituições públicas e de prevenção da ilicitude, corroborando com Montesquieu na medida em "que o poder deve conter os excessos do próprio poder".

\section{A auditoria interna na adminis- tração pública}

Em face do exposto, há de se admitir, ao menos, que o dever de prestar contas, de todos quantos administrem bens públicos em nome dos demais cidadãos, decorre do princípio republicano res publicae, predominante na nossa Constituição; e que, para que possa prestar contas, os administradores públicos precisam estar bem informados sobre os atos e fatos de sua administração. Isso é controle. Não sem motivos, Megginson (1986) menciona que, se a função de controle não for desempenhada efetivamente, as demais funções (planejar, organizar e dirigir) serão de valor limitado na organização, propiciando, na melhor das hipóteses, baixo desempenho e, na pior, caos, fazendo definhar o conceito de eficiência e eficácia na administração pública.

No entanto, é impossível conceber que o administrador público possa estar em todos os locais e exercer diretamente todas as atividades da administração. É necessário delegar responsabilidades e, ao mesmo tempo, controlar essas atividades de forma a assegurar que a organização está funcionando conforme o planejado e o esperado. Nesse sentido, vem em seu auxílio uma importante ferramenta de controle: a auditoria interna.

Ante um universo de recursos e demandas públicas, a auditoria interna mostra-se como parceira do administrador público na consecução dos objetivos de sua gestão. Vale ressaltar que, quando aqui mencionado, o administrador público é todo aquele que tem a responsabilidade de gerir ações que utilizam recursos para fins públicos, não se limitando ao presidente da República, ao governador ou ao prefeito. Há inúmeras autarquias, órgãos, empresas públicas, fundações, institutos, entre outros, e em todos os níveis, que fazem parte do "corpo público da sociedade" e, portanto, são geridos por administradores que, se não foram escolhidos diretamente pelo povo, foram designados por aqueles votados e eleitos pela via democrática.

No Brasil, não existem divulgações de pesquisas sobre as origens da auditoria, sendo somente certo que teve origem inglesa. Segundo Jund:

Apesar de formalmente organizada em 26 de março de 1957, quando formado o Instituto de Contadores 
Público no Brasil, em São Paulo, a auditoria foi oficialmente reconhecida apenas em 1968, por ato do Banco Central do Brasil. O fortalecimento da atividade, todavia, ocorreu em 1972, por regulamentações do Banco Central do Brasil, conselho Federal de contabilidade e Instituto dos Auditores Independentes.(Jund, 2002c).

O mesmo autor Jund (2006) alude ainda que, no âmbito interno da administração pública, conta o gestor público com a auditoria, importante ferramenta de controle interno de sua administração, cuja finalidade básica é a de:

Comprovar a legalidade e legitimidade dos atos e fatos administrativos e avaliar os resultados alcançados, quanto aos aspectos de eficiência, eficácia e econômica da gestão orçamentária, financeira, patrimonial, operacional, contábil e finalista das unidades e das entidades da administração pública, em todas as esferas de governo e níveis de poder, bem como a aplicação de recursos públicos por entidades de direito privado, quando legalmente autorizadas nesse sentido. (JuND, 2006).

Como se vê, a auditoria interna não se confunde com controle interno; no entanto, trata-se de uma área diretamente vinculada à alta administração e que, com autonomia e independência, promove a verificação dos controles internos de todos os setores da organização pública. A auditoria interna verifica e testa os controles internos, em todas as áreas da organização, especialmente as mais nevrálgicas na administração pública, como as áreas financeira e orçamentária, compras e suas licitações, entre outras; validando ou não a sua eficácia, legalidade e segurança. Nesse sentido, Lima e Castro (2003) argumentam que a auditoria atua auxiliando o administrador na tomada de decisões, por meio de relatórios e pareceres, bem como colabora para a evidenciação de erro, omissão ou fraude.

No caso da administração pública, o trabalho interno de auditoria interna possibilita ainda detectar e propor a correção dos desperdícios e procedimentos equivocados, principalmente antecipandose a essas ocorrências, antes da fiscalização dos tribunais de contas. Trata-se, portanto, de uma ferramenta de controle vital para o administrador público e pari passu, dado a natureza de seu trabalho; a auditoria interna também pode ser concebida como um agente de controle social que defende o interesse de toda a sociedade, na medida em que o bem auditado por ela é o bem público.

Assim sendo e lembrando as palavras de Jacoby Fernandes, segundo o qual é “indispensável estruturar os órgãos de modo a que possam cumprir adequadamente as funções que lhes são reservadas", e se a auditoria interna é uma ferramenta de gestão estratégica que visa assegurar uma administração eficaz, eficiente e transparente, por que a maioria dos administradores públicos não inclui na sua gestão a criação de uma auditoria interna?

Sem querer esgotar o assunto porque tal resposta, per si, já seria tema de outro artigo, tamanho o viés de análise possível, dois fatos podem ser destacados que explicam a falta de motivação do gestor público: o primeiro diz respeito ao total desconhecimento por parte do administrador sobre o que é e como trabalha a auditoria interna na administração pública. Esses de alguma forma não conseguem cogitar que auditorias constantes e perenes na sua administração podem, inclusive, 
ampará-lo e assessorá-lo na medida em que, através da auditoria, é possível prever, corrigir e até coibir práticas dissociadas dos objetivos de sua gestão. Por ignorância e preconceitos, o administrador considera que, via de regra, "auditoria é problema". Quando, na realidade, a auditoria aponta soluções para os problemas.

A segunda razão para o administrador público não considerar a criação de uma auditoria interna na sua gestão é a desconfiança de que ficará tolhido, sem liberdade de dirigir a administração da forma que planejou. Isso não corresponde à verdade. $\mathrm{Na}$ realidade, a auditoria interna, longe de ser uma área impositiva ou punitiva, é, ao contrário, uma ferramenta de apoio e assessoramento à gestão. A auditoria interna não toma medidas de correção e, sim, sugere essas medidas, prevendo o impacto das correções nos objetivos da entidade. A auditoria não conduz a gestão para esta ou aquela direção e, sim, organiza relatórios que mostram os melhores caminhos, as boas práticas, os melhores controles, sem, contudo, impor regras de conduta e novos procedimentos que, em ultima análise, são decisões que competem ao próprio gestor público. Ressalte-se ainda que os relatórios e pareceres da auditoria interna possuem caráter opinativo e não obrigatório para a administração, cujos "pontos de melhoria" contidos nos pareceres dos auditores internos podem ou não ser seguidos pelo administrador. Naturalmente que o risco de seguir ou não os pontos de melhoria propostos pelos auditores internos é de decisão do gestor público.

Portanto, como salientado, a auditoria interna age apreciando a atividade pública, sem infligir o modelo gerencial perfeito, corroborando para que a administração e os objetivos sejam eficientemente conduzidos, de modo que o Estado possa "fazer o que deve fazer" e seja impedido "de fazer o que não deve ser feito".

Por essa razão, este artigo apresenta a proposta de criação de auditoria interna em todos os níveis da administração pública brasileira, como elemento de constante análise sobre o controle interno e como interface com o controle externo. Dessa forma, objetiva-se alicerçar o entendimento de que a criação de uma auditoria interna nas organizações públicas, nas três esferas de poder (Executivo, Legislativo e Judiciário), corresponde, a um só tempo, a uma ação de relevância social e um compromisso com a austeridade por parte de todo aquele que detém a responsabilidade de gerir a coisa pública.

\section{A experiência no Instituto de Pesos e Medidas do Estado de São Paulo (Ipem-SP)}

Por meio da Lei 6.985 de 23 de dezembro de 1966 foi criado o Instituto de Pesos e Medidas do Município de São Paulo, respaldando juridicamente atribuições metrológicas exercidas pelo município. Em seguida, no mês de fevereiro de 1967, atendendo a nova política nacional de metrologia, foram criados órgãos estaduais delegados do Instituto Nacional de Pesos e Medidas (INPM), atualmente Instituto Nacional de Metrologia (Inmetro), autarquia federal administrativamente vinculada ao Ministério do Desenvolvimento, Indústria e Comércio Exterior. No mesmo ano, mediante o Decreto $n^{\circ} 47.927$ de 24 de abril, foi criado o Instituto de Pesos e Medidas do Estado de São Paulo (Ipem-SP), com a finalidade de executar serviços técnico-administrativos de pesos e medidas no território do Estado de São Paulo. O Ipem-SP, portanto, é um órgão delegado do Inmetro e uma 
autarquia estadual atualmente vinculada à Secretaria de Justiça e Defesa da Cidadania. O Ipem-SP, como órgão de defesa do consumidor, tem a missão de, nos termos da delegação, executar a política metrológica e de qualidade de produtos e serviços, visando a proteção do consumidor, a orientação para o consumo e a leal concorrência, garantindo, dessa forma, o respeito à sociedade $\mathrm{e}$ o direito à cidadania.

O Ipem-SP, além da atuação preventiva e educativa, também é responsável pela aferição e fiscalização de, por exemplo, taxímetros, balanças industriais e de comércio, bombas de combustível, veículos que transportam cargas perigosas (caminhões-tanque e vagões-tanque), radares em estradas e produtos pré-medidos, tais como: arroz, gás de cozinha, papel higiênico, congelados, entre outros. Por fim, dois outros segmentos estão entre suas atividades: a fiscalização de produtos têxteis e a certificação compulsória de cronotacógrafos (instrumento registrador de velocidade, tempo de direção e distância percorrida pelo veículo), termômetros clínicos, medidores de pressão arterial, e etilômetros (popularmente conhecidos como bafômetros), além de capacetes para motociclista, brinquedos, mamadeiras, fios e cabos, extintor de incêndio, entre outros. O Ipem-SP possui laboratórios de precisão para a análise dos produtos e as ações de fiscalização são realizadas por meio de equipes de agentes fiscais, distribuídas em 13 regionais no interior e quatro na capital.

Em janeiro de 2009, a Superintendência do Ipem-SP foi assumida por Fabiano Marques de Paula e, em seguida, por ato do novo superintendente (2009), foi criada a Auditoria Interna (Audin-SP); sendo importante destacar que entre os órgãos que compõem a Secretaria de
Justiça e Defesa da Cidadania do Estado de São Paulo, o Ipem-SP é o único a possuir uma auditoria interna.

Com a criação da auditoria interna, o Ipem-SP passou a contar com um arcabouço jurídico e administrativo e a exercer dois tipos de auditorias: operacional e especial. A primeira avalia contratos, licitações, legalidade dos atos administrativos, riscos dos procedimentos e dos controles internos e compara o

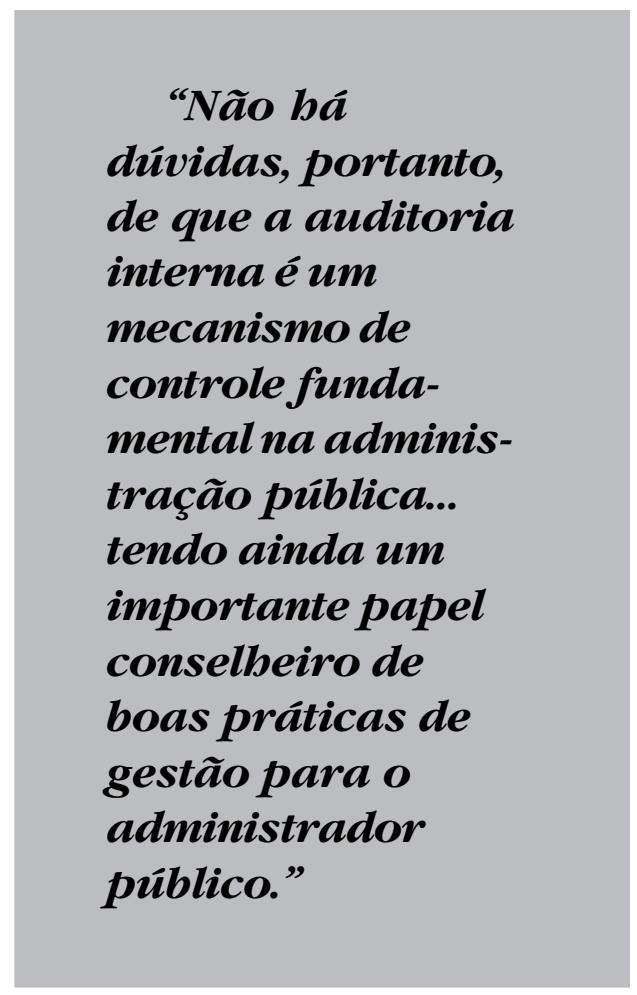

que foi planejado com o que foi alcançado, elaborando relatórios geralmente com recomendações de melhorias. Já a auditoria de natureza especial, no caso do Ipem-SP, realiza averiguação preliminar a fim de atender a denúncias de desvio de conduta de servidores da autarquia no cumprimento de suas tarefas administrativas ou de fiscalização, que foram 
oferecidas, anonimamente ou não, na Ouvidoria ou diretamente na Superintendência. Enquanto a auditoria operacional ocorre mediante planejamento anual, cumprido ao longo do ano pelos auditores internos, as auditorias especiais somente são iniciadas após autorização do próprio superintendente e recebem prioridade de tratamento.

Outra responsabilidade da auditoria interna do Ipem-SP, e de extrema relevância, é a atividade de acompanhamento e facilitação do trabalho de controle externo, no caso, as auditorias externas do Tribunal de Contas do Estado de São Paulo (TCE) e do Inmetro, ao qual o Ipem-SP está vinculado por delegação - ambas realizadas anualmente. $\mathrm{Na}$ Constituição de 1988 existe a obrigatoriedade, por força do artigo 74 item IV, de que os poderes Legislativo, Executivo e Judiciário deem apoio ao controle externo no exercício de sua missão constitucional. Portanto, uma vez criada, a Auditoria Interna deverá ter, entre as suas atribuições, a obrigação de disponibilizar o sistema de controle interno a fim de apoiar e facilitar o trabalho do controle externo (auditorias externas).

Nesse ponto é importante evidenciar o sucesso que representou para o IpemSP a criação da auditoria interna. O destaque junto aos dois órgãos de controle externo merece ser evidenciado, especialmente porque o trabalho dos auditores externos teve a colaboração da auditoria interna na facilitação da própria auditoria externa. Como é sabido, as auditorias dos órgãos de controle externo verificam, como de praxe, inúmeros processos de licitação, fontes de receita, controles patrimoniais, diárias, transportes, recursos humanos, contratos, entre outros itens de verificação. Geralmente essas auditorias ocorrem anualmente, com duração que pode variar de alguns dias a semanas. No caso do Ipem-SP, a última auditoria do TCE foi realizada em três dias e a do Inmetro, de duas a três semanas.

O trabalho da auditoria interna consistiu em aperfeiçoar o atendimento aos auditores de órgãos externos, preparar os funcionários das demais áreas do Ipem-SP para o atendimento ágil às solicitações dos auditores externos, e recepcionar as demandas da auditoria por processos e documentos. É seguro dizer que o fato de existir uma auditoria interna, responsável por organizar o atendimento aos auditores do TCE e do Inmetro, teve, ao menos, três reflexos importantes: o primeiro diz respeito ao fato de que a organização das solicitações e as respostas das áreas tornaram-se mais ágeis, trazendo maior prontidão ao atendimento das solicitações dos auditores; o segundo reflexo bastante significativo foi a economia de tempo e trabalho de funcionários do próprio Ipem-SP, que antes precisavam ficar de prontidão durante as auditorias, deixando de realizar suas tarefas. E o terceiro reflexo foi a economia de tempo do próprio auditor externo que antes precisava localizar pessoas, dirigirse às áreas e entrevistar dirigentes sem, contudo, saber quem eram e onde estavam localizados. Com uma área específica - a auditoria interna - para atender a auditoria externa, o tempo de permanência do controle externo na organização diminuiu, conforme se vê:

A criação pioneira de uma auditoria interna é um dos fatores que nos levam à redução de tempo de trabalho tão significativo no Ipem-SP. O que antes durava 21 dias reduzimos para cinco. Isso nunca foi feito antes. (Inmetro, 2010). 
Portanto, pode-se aferir que a auditoria interna no âmbito da administração pública, além de ser um facilitador para o trabalho do controle externo, age também como interlocutor entre as áreas auditadas e os auditores externos, diminuindo o tempo de auditoria e, consequentemente, reduzindo os custos dessa operação.

Além do viés do atendimento aos órgãos de controle, outros reflexos puderam ser percebidos. Em apenas alguns meses de existência, a auditoria interna foi responsável pela customização de procedimentos, adoção de medidas de segurança em sistemas de informática, revisão de contratos de locação da autarquia e melhoria nos procedimentos administrativos, que resultaram em maior confiabilidade e economia de recursos financeiros.

Contudo, o principal resultado verificado foi a implantação de uma "cultura de parceria" entre os auditores internos e os servidores, na medida em que esses últimos passaram a entender e até mesmo solicitar a presença dos auditores internos, a fim de analisar procedimentos e controles internos, com o fito de verificar o grau de confiabilidade e aperfeiçoá-los e, logo, impactar positivamente o próprio trabalho da área auditada.

Portanto, a experiência do Ipem-SP, em face dos resultados até aqui alcançados, evidencia que a auditoria interna da autarquia está cumprindo com o seu papel de assessorar o administrador público no sentido de monitorar, avaliar e sugerir melhorias de atos e fatos de sua administração, de forma que possa culminar com práticas mais eficientes, eficazes e dentro da legalidade.

\section{Conclusão}

Este artigo, sem querer esgotar o tema, propõe algumas reflexões à guisa de conclusão. A incorporação de uma auditoria interna nos diferentes níveis da administração pública possui algumas dimensões, duas delas particularmente importantes: a primeira, que o gestor público deve gerir a coisa pública seguindo os princípios constitucionais da legalidade, impessoalidade, moralidade, publicidade e eficiência; e a segunda, que a auditoria interna é o instrumento de controle capaz de catalisar informações estratégicas sobre os atos e fatos de sua gestão, inclusive antecipando-se ao controle externo, o que para o gestor público é de extrema importância, tendo em vista que ele responde diante dos tribunais de contas ou outros órgãos externos de controle.

Nesse sentido, importante lembrar ainda que tal exigência de boas práticas de gestão decorre não apenas dos princípios constitucionais que se impõem ao administrador público, que seriam, per si, mais que suficientes, mas também em virtude da prestação de contas a que também está obrigado, seja qual for a esfera governamental em que atue. O Executivo terá de prestar contas anualmente ao Legislativo, dentro do prazo legal estabelecido pelas constituições Federal e estaduais ou pelas leis orgânicas municipais. Assim, os administradores dos órgãos da administração direta e também indireta estão sujeitos ao controle externo, exercido pela União por meio do Congresso Nacional, auxiliado pelo Tribunal de Contas da União; nos estados, pelas assembleias legislativas, com o auxílio dos respectivos tribunais de contas estaduais; e nos municípios, pelas câmaras municipais de vereadores auxiliadas pelo Tribunal de Contas dos Municípios ou órgão equivalente.

Não há dúvidas, portanto, de que a auditoria interna é um mecanismo de controle fundamental na administração 
pública, que zela pelo funcionamento da organização, tendo ainda um importante papel conselheiro de boas práticas de gestão para o administrador público. Dessa forma, não tem coerência dizer que a "auditoria é problema". Ao contrário. Esse paradigma perverso e incoerente deve ser suplantado em face da necessidade da administração pública de controlar e prestar contas sobre o uso do poder.

A Constituição Cidadã de 1988, bem como os demais dispositivos legais, revela os anseios de uma nação por um Estado que seja administrado de forma responsável e competente. Os controles internos e externos estabelecidos no ordenamento jurídico nacional trouxeram bases claras para o agir "politicamente responsável" e o "administrativamente eficiente" do administrador público, que, combinados com a auditoria interna, possam finalmente levar o Estado a um refinamento e aprimoramento na gestão pública brasileira.

(Artigo recebido em maio de 2010. Versão final em abril de 2011).

\section{Referências bibliográficas}

Almeida, Marcelo Cavalcante. Auditoria. São Paulo: Atlas, 1996.

Aтtтьe, William. Auditoria Interna. São Paulo: Atlas, 1986.

Autran, José. Reunião Setorial Sul Sudeste de Órgãos delegados do Inmetro. Disponível em: http://www.ipem.sp.gov.br. Acessado em: 29 de mar. 2010.

Constituição da República Federativa do Brasil de 1998. Disponível em: http:// www.interlegis.gov.br. Acessado em: 29 de março de 2010.

DeCRETo-Lei no 200 de 25 de fevereiro de 1967.

IIA. The Institute of Internal Auditors. Disponível em: htpp://www.theiia.org. Acessado em: 10 de mar. 2009.

Jacoby Fernandes, Jorge Ulisses. Tomada de Contas Especial: processo e procedimento nos Tribunais de Contas e na Administração Pública. $3^{a}$ ed., ver. atual. e ampl. Belo Horizonte: Fórum, 2005.

Jund, Sergio. Auditoria. Rio de Janeiro: Impetus, 2002. - Administração, orçamento e contabilidade pública: teoria e 830 questões. Rio de Janeiro: Elsevier, 2006.

Lima, Diana Vaz de; Castro, Robison Gonçalves de. Contabilidade Pública: Integrando União, Estados e Municípios (Siafi e Siafem). 2.ed. São Paulo: Atlas, 2006.

Megginson, Leon C.; Mosley, Donald C.; Pietri Jr, Paul H. Administração: conceitos e aplicações. São Paulo: Harper \& How do Brasil, 1986.

Montesquieu, Charles de Secondat, Baron de. O Espirito das Leis. $2^{a}$ ed. São Paulo: Martins Fontes, 1996.

Morin, Edgar. Ciência com Consciência. Rio de Janeiro: Bertrand, 1996. 
MeIrelles, Hely Lopes. Direito Administrativo Brasileiro. 16 edição. São Paulo: Revista dos Tribunais, 1988.

Senado Federal. Pronunciamento da Constituição Federal Brasileira de 1988. Disponível em: http:/ /www.senado.gov.br/comunica/museu/ulisses.htm. Acessado em: 02 de mar. 2010. Silva, José Afonso da. Curso de direito constitucional positivo. 17. ed. rev. atual. São Paulo: Malheiros, 2000a. 


\section{Resumo-Resumen-Abstract}

\section{Auditoria interna como instrumento de controle social na administração pública Célia Marcola}

Sob o ponto de vista constitucional os controles interno e externo somam-se a fim de promover responsabilização permanente dos gestores públicos em torno dos princípios constitucionais da administração pública: legalidade, impessoalidade, moralidade, publicidade e eficiência. Neste artigo a argumentação segue no sentido de incrementar as discussões acerca da importância de que em todos os níveis da administração pública e nos três poderes - Legislativo, Executivo e Judiciário seja implantada a auditoria interna, como unidade responsável pela análise do sistema de controle interno e a interlocução com o controle externo. Embora a administração pública no Brasil ainda se estruture hibridamente sob o sistema burocrático e o sistema gerencial, o fato é que os administradores públicos possuem na auditoria interna importante mecanismo gerencial que, como regra, contribui para detectar e propor a correção dos desperdícios e procedimentos equivocados, principalmente antecipando-se a essas ocorrências. Neste artigo, é apresentado ainda o exemplo da criação da auditoria interna no Instituto de Pesos e Medidas do Estado de São Paulo (Ipem-SP), sua interlocução com o Controle Externo e os resultados no âmbito da autarquia.

Palavras-chave: Controles interno e externo, auditoria interna, mecanismo gerencial

\section{Auditoría interna como instrumento de control social en la administración pública Célia Marcola}

Bajo el punto de vista constitucional los controles interno y externo se suman, con el objeto de promover la responsabilización permanente de los funcionarios públicos en torno a los principios constitucionales de la administración pública: legalidad, impersonalidad, moralidad, transparencia y eficiencia. En este artículo los argumentos que tienen por objeto aumentar los debates sobre la importancia de que en todos los niveles de la administración pública y en los tres poderes Legislativo, Ejecutivo y Judicial sea implantada la auditoría interna como una unidad encargada de analizar el sistema de control interno y la interlocución con el control externo. Aunque la administración pública del Brasil aún presente una estructura híbrida bajo el sistema burocrático y el sistema de gestión, lo que pasa es que los administradores públicos tienen un importante mecanismo de gestión en la auditoría interna que, por lo general, ayuda a detectar y a proponer los procedimientos de corrección de los desperdicios y de los equívocos, especialmente con previsión de esos hechos. En este artículo se presenta como un ejemplo más la creación de la auditoría interna en la Oficina de Pesos y Medidas del Estado de São Paulo (Ipem-SP), su diálogo con el Control Externo y sus resultados.

Palabras clave: controles interno y externo, auditoría interna, mecanismo de gestión

\section{Internal audit as an instrument of social control in public administration Célia Marçola}

Under the constitutional point of view the controls - internal and external - are added to promote accountability of public officials standing around the principles of constitutional government: lawfulness, impersonality, morality, transparency and efficiency. In this article the arguments are aimed at increasing discussions about the importance of all levels of public administration and in the three branches: legislative, executive and judiciary, be deployed to internal audit as a unit responsible for examining the system of internal control and communication with the external control. Although the government in Brazil would still put on hybrid and under the bureaucratic system and management system, the fact is that public officials have an important in the 
internal audit management mechanism which as a rule, helps to detect and suggest the correction of erroneous procedures and waste, especially in anticipation of such occurrences. This article is presented as one more example of the creation of internal audit at the Office of Weights and Measures of the State of São Paulo - Ipem-SP, his dialogue with the External Control and results within the municipality.

Keywords: internal and external controls, internal audit, management mechanism

Célia Marçola

Especialista em Administração pela Universidade de São Paulo (USP). Atua como auditora-chefe e responsável pela implantação da Auditoria Interna do Instituto de Pesos e Medidas do Estado de São Paulo (Ipem-SP). Contato: cmarcola@sp.gov.br 